\title{
Synergistic Teaching Model Based on Community of Inquiry
}

\author{
Ting Zhou \\ School of Arts and Sciences, Shaanxi University of Science and Technology, Xi'an, Shaanxi 710021, China \\ zhouting@sust.edu.cn
}

Keywords: Community of Inquiry; Synergistic Teaching Model; Higher Education; College English

\begin{abstract}
Firstly, this paper briefly describes the current situation of traditional college English teaching in China, analyzing its deficiency. Then the paper discusses the application of MOOC in Chinese universities and concludes that it is necessary to build a new model to make full use of the advantages of the both teaching methods. After that, the paper introduces the CoI model and discusses the necessity of applying CoI to college English teaching. And in the end proposal for a synergistic teaching model based on CoI for Chinese college English teaching is put forward, which the author believes will develop students' critical thinking, sense of exploration, and an ability of self-study, satisfying the requests of students in different levels.
\end{abstract}

\section{Introduction}

Traditional English Teaching in Chinese University. College English teaching in China generally proceeds in large class with sixty to a hundred students in one room and class time is limited, about 4 hours per week. Students' English levels are different and therefore they have different expectations for English class. However, compelled by the teaching request, for instance, finishing required content, Band 4 exams, etc. teachers have to perform as knowledge deliverer. Hence English classes are frequently teacher centered and content centered. Besides, in this condition it is hard to organize effective activities meanwhile finishing required teaching content. Even if teachers tried some activities in class, most students are not eager to participate in either for lack of confidence or lack of ability or interest.

Governmental Advocacy. In 2010 Chinese government declared the planing outline for the reform and development of education from 2010-2020, which advocated innovating online teaching model and developing distance learning with high quality. It encouraged teachers to apply modern information technology and reform teaching method to enhance teaching effect and students to develop autonomic learning by applying information technology as well. [1]

The Application of MOOC in Chinese University. Since the introduction of MOOC(Massive Open Online Courses) to China, it is favored by educationist. This research searched MOOC related to English from the three most famous Chinese MOOC platforms and finally found out 29 courses related to English and 4 college English courses. It is clear that courses related to English is too limited for students to choose. Most of these courses last only for one term but traditional college English class at school lasts for four terms. In other word, the courses on line are neither complete nor systematic. On the other hand, these courses rarely organize group activities, mutual help, exhibit achievement or offer instant reply to questions. Besides, these courses do not cooperate with traditional courses at school. Thus teaching at school could not synergize online learning and vice versa. Actually the application of MOOC in university is not promising as well. Based on Sun Yun's research in Shaanxi, only $7.8 \%$ of students frequently take MOOC courses. The top reasons of low application are monotonous interaction, lack of complete course system, heavy school work and imperfectness of platform. [2](SunYun, 2015) Based on Li Jiao's research in Ji Lin, only 23.99\% of students have ever taken MOOC courses, 65.96\% of whom have ever dropped out of the course halfway. The main reasons for quitting are boring courses, unaccustomed to new learning method, 
lack of reply to questions and so on. The same research showed that $51.04 \%$ of learners need instruction. [3](Li Jiao, 2016).To sum up, MOOC has the potential to impact college English teaching in university, but MOOC could not play its role independently. It is the best time to search for a new synergistic teaching model which would make full use of the advantages of both.

\section{Brief Introduction of Community of Inquiry Framework}

The community of inquiry framework(CoI) is a model for dynamic online learning and blended learning, which was firstly promoted by D.R.Garrison and Terry Anderson based on critical thinking and practical inquiry."The model of this Community of Inquiry assumes that learning occurs within the community through the interaction of three core elements: cognitive presence, social presence, and teaching presence.” [4](Garrison, D.R., 2000)

"The element in this model that is most basic to success in higher education is cognitive presence. This term here is taken to mean the extent to which the participants in any particular configuration of a community of inquiry are able to construct meaning through sustained communication." [4](Garrison, 2000) Garrison explained that cognitive presence is manifested through the practical inquiry process which includes four phases: triggering event, exploration, integration and resolution; and figured out fifteen specific indicators. [5](Garrison, 2001)

"Social presence is defined as the ability of participants in the Community of Inquiry to project their personal characteristics into the community, thereby presenting themselves to the other participants as 'real people'.” [4](Garrison, 2000) Rourke divided social presence into 3 categories: affective responses, interactive responses, and cohesive responses with twelve specific indicators. [6](Rourke , 2007)

Anderson, Rourke, Garrison and Archer defined "teaching presence as the design, facilitation, and direction of cognitive and social processes for the purpose of realizing personally meaningful and educationally worthwhile learning outcomes.” [7](Anderson, 2001) Anderson specified the coding scheme for teaching presence as instructional design and organization, facilitating discourse, and direct instruction with eighteen specific indicators. [7]

Effective learning experience occurs within the community through the interaction of three core presences. The more overlapped area appears, the better learning experience exists.

\section{The Application of CoI in College English Teaching}

Cognitive Presence. The four phases of cognitive presence agrees with the process of knowledge acquisition in high level education because advanced education is not only to deliver knowledge but also to cultivate students' ability of discovering problems, exploring information, absorbing knowledge and resolving problems. A guide to college English teaching has made it clear that while strengthening students' English ability, teachers also need to cultivate students' ability of self-study. [8](Wang, 2016) In fact, in traditional English class teachers conduct this process frequently as well, since it agrees with the teaching goal and students will benefit from this teaching way in long run.

Social Presence. Humanistic learning approach points out that the natural willing and potential of learning would be released in suitable condition and individuals can study well only in psychological security. [9](Che, 2004) Establishing suitable social presence would help students to build confidence, satisfactory and sense of pride, so that they will have passion on study. Meanwhile the real performance of students will help teachers to assess students and their own work and adjust teaching in time. Chinese students are taught to be modest from childhood and they fear of speaking their points in public, so it is hard to build suitable social presence in traditional class. However they are braver online, because they feel safer. But the suitable social presence not only needs students' performance online but also off line and also teachers participation online and off line. Teachers' guidance, assistance, evaluation, organization and students' cooperation and collaboration play key roles in the building of social presence. 
Teaching Presence. Teaching presence enhance social and cognitive presence for the purpose of realizing educational outcomes.[4](Garrison, 2000) It includes all teaching methods and activities online and off line and is appropriate in higher education and in synergistic teaching.

CoI. Higher education is to foster a sense of exploration, critical thinking, and ability of self-study. The CoI is grounded in the critical thinking and support critical thinking and social collaboration.

"Distance education models which are based upon one-way media cannot be expected to facilitate a community of inquiry. It is argued here that some opportunity should be provided to support critical discourse and the development of a community of inquiry."[10](Anderson, 1995) Thus, to build CoI for college English teaching, well designed traditional courses are necessary. They can be the introductory course, direct lecture, courses for solving problems, practicing, reviewing, test and enlightening courses, which are decided by learning content and students level.

\section{Synergistic Teaching Model Based on CoI}

This research puts forward a synergistic teaching model based on CoI as is shown in figure 1 . It includes traditional English course in university and effective MOOC course on line and other valuable teaching materials and platforms assisting teaching and learning online(such as related materials on website and Wechat, blog, QQ, etc.). The three elements are not blended casually but well organized by teachers and students in the community, so traditional English course and MOOC synergize with each other while other valuable teaching materials and platforms online assist them. This model emphasizes teachers' guidance, organization, assistance, evaluation, and students' inquiry, exploration, thinking, collaboration, self-expression and mutual evaluation. By building CoI in synergistic teaching model teachers give students opportunity to undergo meaningful and valuable learning experience in higher education.

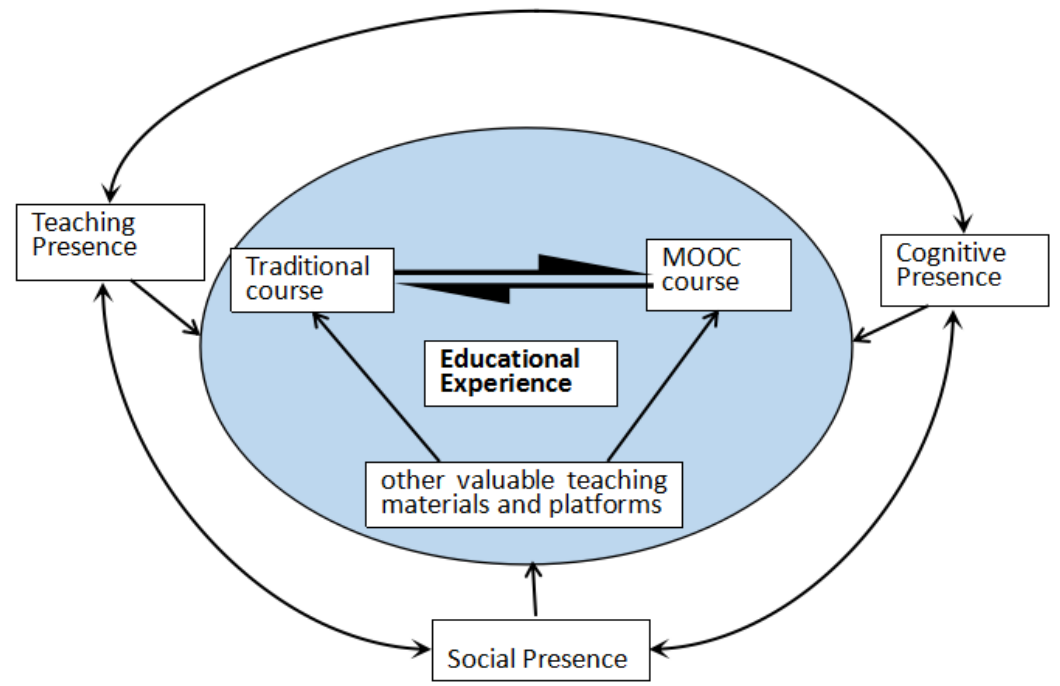

Figure 1. Synergistic Teaching Model

In this model teachers should organize a qualified team to develop complete and systematic courses and decide whether to deliver the knowledge points they prepared on line or off line. The traditional course off line and MOOC synergize with each other based on the same teaching goal and outline. MOOC and useful learning materials can be approached by PC, ipad, intelligent mobile phone and other mobile devices. For teachers, they trigger, inspire students and deliver knowledge on line. When students master the introductory knowledge, they come to traditional class with their questions and inquiry. Teachers answer their questions, give lecture to fill in the blank in the complete knowledge system face to face and give them suggestions on advanced information exploration. With teachers' guidance, students return to network to explore and enlarge their knowledge and do practice. And again they return to traditional class to participate in class activities designed by teachers on purpose, applying knowledge into practice and get teachers' assessment and help. Teachers have the responsibility to supervise students' performance both in class and on line in every possible means. They can use blog to recommend valuable information and issue notice by QQ or Wechat, or organize 
various kinds of activities with help of other platforms on line. For students, they acquire knowledge from a team of teachers. Besides they are encouraged to interact with teachers, other students, learning materials and internet. What's more, they should think creatively and critically to trigger a new turn of learning.

\section{Synergistic Teaching Model Based on CoI for Chinese College English Teaching}

Considering Chinese teaching condition and characteristics, the research designs a synergistic teaching model based on CoI for Chinese college English teaching, as is shown in figure 2.

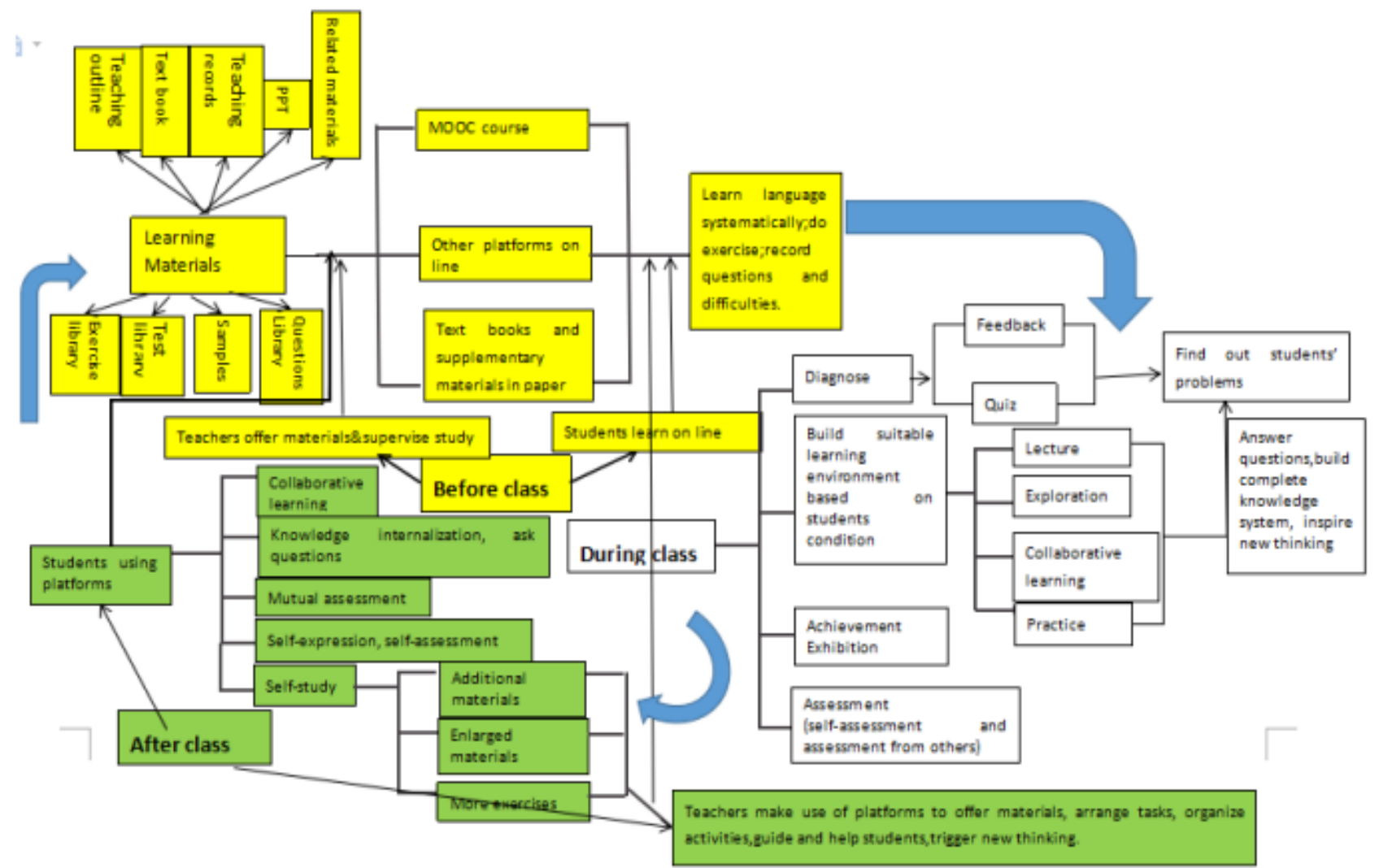

Figure 2. Synergistic Teaching Model Based on CoI for Chinese College English Teaching

This model divides educational experience into three parts: before, during and after traditional class. Before traditional class students take MOOC and make use of it and other platforms on line to approach learning materials offered by teachers. Students try to teach themselves with help of internet, paper books and supplementary materials in paper. They learn language, do exercise in exercise library, record their questions and difficulties. During the traditional class, teachers find out students' problems and teach on purpose. They need to help students to build complete knowledge system and highlight key points. It is teachers' responsibility to build suitable learning environment and organize effective activities based on students' English levels. If the class were too large and students' English levels were different, they would cooperate with each other or teachers would arrange different tasks for different students or organize some activities on line. Teachers also assess students' performance and exhibit their achievements. After class students continue further study on line by collaborative learning, self-study, knowledge internalization and asking questions in learning community. They also share their learning experience and evaluate each others' work in this community. In this phase teachers make use of platforms to offer materials, arrange tasks, organize activities, guide and help individual students, trigger new thinking which will lead to new turn of educational experience. The whole process of teaching moves forward in a screw type.

\section{Significance of Synergistic Teaching Model}

This new model of teaching collects a group of teachers' intelligence and knowledge, so it saves 
teachers' labour, offers sufficient knowledge and makes use of these teachers' experience to contribute to teaching. Besides, this model makes use of advantages of traditional teaching, MOOC and other platforms online, so teachers have more time and space to satisfy students in different English levels. Teachers could give them different tasks, activities, homework and assistance on purpose. For students, they have free environment to take part in teaching activities, speak out their points, participate in discussion, collaboration, mutual assessment, achievement exhibition, etc, and they will easily develop critical thinking, ability of self-study and sense of exploration. These are the qualified educational experiences in higher education.

\section{Summary}

The design of the synergistic teaching model fully considers the building of CoI. Teachers in this community must adjust each element to make sure of building social presence, cognitive presence and teaching presence. Students in this community must actively participate in to realize the biggest overlap of the three presences. This model follows the rule of teaching and learning in university, so it will be enlightening in higher education.

\section{References}

[1] http:// www.china.com.cn/policy/txt/2010-03/01/content_19492625_6.htm

[2] Yun Sun, Junye Li.(2015). Research on the development status of mooc and the educational reform of Shaanxi university. Shaanxi education, 4: 37-38 (In Chinese)

[3] Jiao Li, Bofu Zhang.(2016). The investigation and analysis of the current situation of college students' studying in undergraduate universities. Science Tribune, 12: 188-189 (In Chinese)

[4] Garrison, D.R., Anderson, T., Archer, W.(2000). Critical Inquiry in a Text-Based Environment: Computer Conferencing in Higher Education. Internet\& Higher Education, 2(2-3):87-105

[5] Garrison, D.R., Anderson, T., Archer, W.(2001). Critical Thinking, Cognitive Presence, and Computer Conferencing in Distance Education. American Journal of Distance Education,15:7-23

[6] Rourke, L., Anderson, T., Garrison, D.R., Archer, W.(2007). Assessing Social Presence in Asynchronous Text-based Computer Conferencing. Journal of Distance Education, 14:50-71

[7] Anderson, T., Rourke, L., Garrison, D.R., Archer, W.(2001). Assessing Teaching Presence in a Computer Conferencing Context. Journal of Asynchronous Learning Networks, 5:1-17

[8] ShourenWang. (2016). A guide to college English teaching, Foreign Language World, 3: 2-10 (In Chinese)

[9] Wenbo Che.Humanistic psychology. Hangzhou: Zhejiang education press, 2004 (In Chinese)

[10]Anderson, T.D., Garrison, D.R.(1995).Critical Thinking in Distance Education: Developing Critical Communities in an Audio Teleconference Context. Higher Education, 29 (2) :183-199 